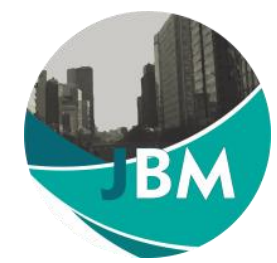

\author{
Jurnal Bisnis dan Manajemen \\ http://jurnal.unmer.ac.id/index.php/jbm/index
}

Volume 8 No 1

2021

HIm. 64 - 74

\title{
Peran Worklife Balance dan Stres Kerja terhadap Kinerja Karyawan dengan Organizational Citizenship Behavior sebagai Variabel Mediasi
}

Submitted Date:

5 Januari 2021

Accepted Date:

20 Januari 2021
Miftahul Hikmah

Universitas Andalas

miftahikmah03@gmail.co.id

Hendra Lukito

Universitas Andalas

hendralukito71@gmail.com

\begin{abstract}
:
The purpose of this study is to determine and analyze the effect of Worklife balance, Job Stress and Organizational Citizenship Behavior (OCB) on employee performance, Worklife balance and Job Stress on OCB, Worklife Balance and Job Stress mediated by OCB on employee performance. This of explanatory research with cross sectional method. The data analysis technique used is partial least square. Respondents in this study were 50 people who were employees of PT PLN (Persero) UP2B Sumbagteng. The results of this study found that: Worklife Balance and OCB have a significant effect on employee performance, a good Worklife Balance and OCB for employees will improve their performance. Work stress is contradictory and has a significant effect on OCB and employee performance. Stress experienced by employees will have an impact on low OCB and performance. The magnitude of the effect of Worklife Balance on OCB is shown by the coefficient of determination $R^{2}$ of 0.261 or $26,1 \%$. The magnitude of the influence of OCB on employee performance is shown by the coefficient of determination $R^{2}$ of 0.375 or $37,5 \%$ and then there is also an indirect relationship with partial mediation by the OCB variable.
\end{abstract}

Keywords: Employee Performance, Job Stres, Organizational Citizenship Behavior, Worklife Balance

Abstrak:

Penelitian ini bertujuan untuk menganalisis pengaruh Worklife Balance, Stres Kerja dan Organizational Citizenship Behavior (OCB) terhadap Kinerja Karyawan, Worklife balance dan Stres Kerja terhadap OCB, Worklife Balance dan Stres Kerja yang diperantarai oleh OCB terhadap Kinerja karyawan. Jenis penelitian Explanatory dengan metode Cross sectional, Teknik analisis data yang digunakan adalah partial least square. Jumlah responden dalam penelitian ini adalah 50 orang yang merupakan Karyawan PT PLN (Persero) UP2B Sumbagteng. Hasil penelitian ini menemukan bahwa Worklife Balance dan OCB berpengaruh signifikan terhadap kinerja karyawan, semakin tinggi Worklife Balance dan OCB pada karyawan maka akan semakin tinggi kinerjanya. Stres kerja bertentangan dan berpengaruh signifikan terhadap OCB dan kinerja karyawan, semakin tinggi Stres yang dialami oleh karyawan, maka akan semakin rendah sikap OCB dan kinerjanya. Besarnya pengaruh Worklife Balance terhadap OCB ditunjukkan oleh koefisien determinasi $\mathrm{R}^{2}$ sebesar 0.261 yang menunjukkan bahwa pada PT PLN (Persero) UP2B Sumbagteng OCB dipengaruhi oleh Worklife Balance sebesar 26,1\%. Besarnya pengaruh OCB terhadap Kinerja karyawan ditunjukkan oleh koefisien determinasi $\mathrm{R}^{2}$ sebesar 0.375 yang menunjukkan bahwa pada PT PLN (Persero) UP2B Sumbagteng Kinerja karyawan dipengaruhi oleh OCB sebesar $37,5 \%$ dan juga menunjukkan hubungan tidak langsung dengan mediasi parsial oleh variabel OCB.

Kata Kunci: Kinerja Karyawan, Organizational Citizenship Behavior, Stres Kerja, Worklife Balance.

JEL Classification: 015 


\section{Latar Belakang}

Dalam dunia bisnis saat ini banyak tuntutan untuk menciptakan kinerja karyawan yang tinggi demi pengembangan perusahaan. Perusahaan harus mampu membangun dan meningkatkan kinerja di dalam lingkungannya. Kinerja adalah tindakan dan perilaku yang di bawah kendali individu yang berkontribusi terhadap tujuan organisasi (Bruggen, 2015). Dalam konteks organisasi, karyawan dipandang sebagai aktor penting dalam menentukan keberlanjutan organisasi (Thevanes \& Arulrajah, 2017). Perusahaan mencari faktor-faktor berbeda yang dapat menghasilkan sikap dan perilaku kerja yang positif dari karyawan yang pada akhirnya meningkatkan kinerja mereka (Hassan et al., 2014). Lebih jauh, meningkatkan Worklife Balance juga berkontribusi untuk mengurangi absensi dan pergantian karyawan. Worklife Balance adalah tentang menciptakan dan memelihara lingkungan kerja yang mendukung dan sehat, yang akan memungkinkan karyawan untuk memiliki keseimbangan antara pekerjaan dan tanggung jawab pribadi dan dengan demikian memperkuat loyalitas dan produktivitas karyawan. Temuan empiris menunjukkan bahwa karyawan yang merasa baik dan mengalami stres yang terbatas di tempat kerja dan di rumah lebih cenderung merasa puas dengan pekerjaan mereka (Wright \& Cropanzano, 2000).

Penelitian sebelumnya mengenai worklife balance banyak menemukan fakta bahwa tingkat stres ikut dipengaruhi. Hal ini dipicu oleh kepuasan hidup,kepuasan kerja, kesulitan dalam bekerja, masalah dalam keluarga, depresi,absensi, komitmen dalam berorganisasi dan tingkat kinerja (Fisher et al., 2009). Stres merupakan suatu keadaan dimana seseorang mengalami ketegangan karena adanya kondisi yang mempengaruhinya, kondisi tersebut dapat diperoleh dari dalam diri seseorang maupun lingkungan diluar diri seseorang. Stres dapat menimbulkan dampak yang negatif terhadap keadaan psikologis dan biologis bagi karyawan. Namun, stres kerja tidak hanya berdampak pada karyawan kinerja, tetapi bisa menjadi penyebab negatif seperti kelelahan, kurang dorongan untuk bekerja, pergantian karyawan, ketidaksetiaan dan kurangnya ketepatan waktu (Glazer \& Beehr, 2005).

Worklife Balance dapat memotivasi karyawan untuk terlibat dalam Organizational Citizenship Behavior (OCB) di tempat kerja yang pada akhirnya sangat mempengaruhi kinerja organisasi mereka secara keseluruhan (Harikaran \& Thevanes, 2018). OCB adalah kondisi dimana pekerja sanggup melaksanakan pekerjaannya dengan melampaui persyaratan minimum dari deskripsi pekerjaan mereka, menyarankan peningkatan kinerja dan peningkatan efisiensi kelompok kerja (Chelagat et al., 2015). Dalam beberapa penlitian sebelumnya menunjukkan bahwa Organizational Citizenship Behavior (OCB) sering dijadikan sebagai variable mediasi, seperti penelitian (Harikaran \& Thevanes, 2018) Hubungan antara Worklife Balance, OCB dan organisasi kinerja yang menyimpulkan bahwa Worklife Balance dianggap sebagai salah satu faktor diperhatikan dalam praktik kinerja tinggi untuk mengembangkan sikap positif yang terkait dengan pekerjaan di antara karyawan perusahaan organisasi. Akhirnya, sikap positif yang terkait dengan pekerjaan berkontribusi untuk mendorong lebih banyak OCB karyawan yang berubah mengarah untuk meningkatkan kinerja organisasi. Penelitian dari (Maharani et al., 2013) yang menguji Pengaruh Kepuasan kerja terhadap Kinerja karyawan dengan OCB sebagai variable Mediasi ditemukan jika karyawan puas, ia akan berkontribusi peran lebih tinggi.

PT PLN (Persero) Unit Pelaksana Pengatur Beban Sumatera Bagian Tengah yang disingkat dengan UP2B Sumbagteng merupakan salah satu unit dari PT PLN (Persero) Unit Induk Penyaluran dan Pusat Pengatur Beban Sumatera (UIP3BS). Wilayah Kerja PT PLN (Persero) UP2B Sumbagteng adalah meliputi 3 (tiga) propinsi yaitu Jambi, Sumatera Barat, dan Riau. Aspek kesiapan pengelolaan operasi sistem tenaga listrik merupakan indikator utama yang menentukan kinerja PT PLN (Persero) UP2B Sumbagteng. Pencapaian indikator kinerja selama 5 (lima) tahun terakhir seperti terlihat pada tabel 1. Dapat dilihat bahwa Total Nilai Kinerja UP2B Sumbagteng dari tahun 2017 sampai 2018 mengalami penurunan. Hal ini memberikan indikasi bahwa Kinerja pegawai UP2B Sumbagteng perlu mendapatkan perhatian dan masih perlu di tingkatkan untuk pencapaian Kinerja Maksimal. Berdasarkan hasil penelitian sebelumnya terkait Kinerja, Worklife Balance, Stres Kerja dan OCB serta adanya penurunan kinerja di perusahaan tempat peneliti bekerja, membuat peneliti tertarik untuk melakukan penelitian dan berharap dapat memberikan masukan pada Perusahaan terutama hal-hal yang terkait Worklife Balance, stres kerja dan OCB untuk meningkatkan kinerja karyawan. Didukung penelitian sebelumnya mengenai Worklife Balance banyak menemukan fakta bahwa masalah pribadi bisa saja mempengaruhi kinerja karyawan saat bekerja. Hal ini bisa terkait dengan kepuasan dalam kehidupan pribadi, kepuasan kerja, kesulitan dalam bekerja, masalah dalam keluarga, depresi, absensi, komitmen dalam berorganisasi dan tingkat kinerja (Fisher et al., 2009). Dibutuhkan lingkungan psikologis yang positif agar keseimbangan tercapai antara suatu tugas dan kewajiban lain di luar pekerjaan (Sen \& Hooja, 2015). Diharapkan praktek ini dapat memicu kinerja seseorang sehingga pekerja akan cenderung nyaman dalam pekerjaannya, bersemangat dalam melakukan tugas dan tanggungjawabnya. 


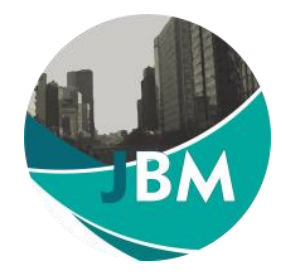

Jurnal Bisnis dan Manajemen

http://jurnal.unmer.ac.id/index.php/jbm/index

Volume 8 No 1

2021

HIm. 64 - 74

Tabel 1. Kinerja UP2B Sumbagteng Tahun 2014 - 2018

\begin{tabular}{cccccc}
\hline PERSPEKTIF & 2014 & 2015 & 2016 & 2017 & 2018 \\
\hline $\begin{array}{c}\text { Kinerja Utama } \\
\text { (Standar Nilai 50) } \\
\text { Proses Bisnis } \\
\text { (Standar Nilai 15) }\end{array}$ & 50 & 44.1 & 49.39 & 53.25 & 50.54 \\
$\begin{array}{c}\text { SDM } \\
\text { (Standar Nilai 10) } \\
\text { Keuangan }\end{array}$ & 18 & 17 & 14 & 11 & 11.05 \\
$\begin{array}{c}\text { (Standar Nilai 15) } \\
\text { Kepemimpinan / Kepatuhan } \\
\text { (Standar Nilai 10) }\end{array}$ & 15.07 & 18.74 & 18.55 & 17.74 & 15.87 \\
\hline $\begin{array}{c}\text { TOTAL NILAl } \\
\text { (100) }\end{array}$ & 7.52 & 6 & 5.74 & 5.7 & 5.7 \\
\hline PT PLN (Persero) UP2B Sumbagteng, 2020 & $\mathbf{9 8 . 3 2}$ & $\mathbf{9 5 . 8 4}$ & $\mathbf{9 8 . 6 8}$ & $\mathbf{9 6 . 2 9}$ & $\mathbf{9 2 . 7 5}$ \\
\hline
\end{tabular}

Disamping terganggunya Worklife Balance dan terjadinya Stres di tempat kerja juga meminimalkan kemampuan pengambilan keputusan, karena ini karyawan tidak memiliki motivasi yang cukup untuk mengambil inisiatif dan membuat keputusan sendiri. Pembinaan dan pelatihan karyawan pada manajemen stres diperlukan untuk membantu mereka mengurangi stres agar berhasil dalam mengatasi masalah sehingga mereka dapat meningkatkan potensi, mempertimbangkan dampak positif dari masa kerja terhadap kinerja (Yozgat et al., 2013). Begitu juga dengan OCB muncul pada diri seorang karyawan apabila yang bersangkutan merasa mendapatkan keseimbangan antara kehidupan pribadi dengan kehidupan kerjanya. Dengan demikian diduga bahwa worklife balance dan stress kerja berperan sebagai prediktor bagi OCB. Ada tiga faktor internal penting yang mempengaruhi OCB yaitu moral karyawan, komitmen karyawan, serta motivasi. OCB selain menjadi perilaku sukarela juga menjadi perilaku yang terbentuk dari banyak faktor baik faktor internal maupun faktor eksternal. Salah satu faktor eksternal pembentuk OCB pada karyawan adalah faktor lingkungan. Sehingga dapat dikatakan bahwa organisasi bisa membentuk OCB karyawan dengan cara menciptakan lingkungan atau iklim yang kondusif yang dapat merangsang karyawan untuk menunjukkan (Djati, 2018). Berdasarkan latar belakang di atas, penulis tertarik untuk meneliti Pengaruh Worklife Balance dan Stres Kerja terhadap Kinerja Karyawan di PT PLN (Persero) UP2B Sumbagteng yang diperantarai oleh OCB.

\section{Literature Review}

Kinerja adalah tindakan dan perilaku yang di bawah kendali individu yang berkontribusi terhadap tujuan organisasi (Bruggen, 2015). Sementara ini menurut Dee K. Knight (2007) kinerja ditandai sebagai tingkat dimana karyawan melaksanakan tugas, tanggung jawab, dan tugas. Indikator untuk mengukur kinerja karyawan secara individu ada enam indikator, yaitu Kualitas, Kuantitas, Ketepatan waktu, Efektivitas, Kemandirian dan Komitmen kerja (Robbins et al., 2012).

Delecta (2011) Work-Life Balance didefinisikan sebagai kemampuan individu untuk memenuhi pekerjaan dan komitmen berkeluarga mereka, serta tanggung jawab non-pekerjaan lainnya. Sementara itu Ganapathi (2016) berpendapat bahwa Worklife balance adalah kemampuan individu untuk menyeimbangkan antara tuntutan pekerjaan dengan kebutuhan pribadi serta keluarganya seperti komitmennya dalam keluarga dan tanggungjawab diluar pekerjaan lainnya. Fisher et al. (2009) menemukan dimensi pembentuk Worklife balance yaitu WIPL (Work Interference Personal Life), PLIW (Personal Life Interference Work), PLEW (Personal Life Enhancement of Work), WEPL (Work Enhancement of Personal Life).

Stres kerja adalah suatu kondisi ketegangan yang menciptakan adanya ketidakseimbangan fisik dan psikis, yang mempengaruhi emosi, proses berpikir, dan kondisi seorang karyawan (Gaol, 2016). Sedangkan stres menurut Gibson et al. (2012) adalah as an adaptive response, mediated by individual differences, that is a consequence of any action, situation, or event that places special demands on a person. Indikator dari stres kerja menurut Robbins et al. 
(2012), yaitu: Tuntutan tugas, Tuntutan peran, Tuntutan/tekanan antar pribadi, Struktur organisasi yang tidak jelas, Kepemimpinan organisasi memberikan kesan tidak nyaman.

Penelitian Mohamed (2016) bahwa OCB adalah jenis perilaku yang dapat didefinisikan sebagai perilaku yang tidak ditentukan oleh deskripsi dalam kontrakpekerjaan, bukan perilaku yang bisa dilatih tapi perilaku yang diinginkan karena berpengaruh positif organisasi dan pekerja. Beberapa bahkan menganggap perilakunyasinergis dengan kinerja organisasi. Pendapat lain, OCB merupakan istilah yang digunakan untuk mengidentifikasi perilaku yang yang berbeda yang diharapkan masuk dalam suatu organisasi, dimana karyawan bertindak secara psikologi dan berperan formal dalam Kinerja (Goudarzvandchegini et al., 2011). Indikator Organizational Citizenship Behavior (OCB) adalah Altruism (Perilaku karyawan dalam menolong rekan kerjanya yang mengalami kesulitan dalam situasi yang sedang dihadapi baik mengenai tugas dalam organisasi maupun masalah pribadi orang lain), Conscientiousness (Perilaku yang ditunjukkan dengan berusaha melebihi yang diharapkan perusahaan), Sportmanship (Perilaku yang memberikan toleransi terhadap keadaan yang kurang ideal dalam organisasi tanpa mengajukan keberatan-keberatan), Courtessy (Menjaga hubungan baik dengan rekan kerjanya agar terhindar dari masalah - masalah interpersonal) Civic Virtue (Perilaku yang mengindikasikan tanggung jawab pada kehidupan organisasi).

Dalam penelitian ini secara teoritis juga menjelaskan terdapat dua Variabel bebas yaitu worklife balance dan Stres kerja serta dua variabel terikat yaitu Organizational Citizenship Behavior (OCB) dan Kinerja Karyawan, Adapun hubungan antar variabel tersebut: Kinerja dari seorang karyawan dapat dipengaruhi oleh beberapa variabel diantaranya Organizational Citizenship Behavior (OCB), worklife balance dan stress kerja dari karyawan tersebut. Perilaku Organizational Citizenship Behavior adalah sikap membantu yang ditunjukkan oleh anggota organisasi, yang sifatnya konstruktif, dihargai oleh perusahaan tapi tidak secara langsung berhubungan dengan produktivitas individu (Steers, 1996) tidak bisa lepas dari Kondisi fisik dan psikis yang prima dari karyawan, yang dalam penelitian ini dijadikan objek oleh peneliti adalah Stres kerja adalah sesuatu kondisi ketegangan yang menciptakan adanya ketidakseimbangan fisik dan psikis yang mempengaruhi emosi, proses berpikir, dan kondisi seorang karyawan (Rivai,2004) dan Worklife balance adalah konsep luas yang melibatkan penetapan prioritas yang tepat antara pekerjaan (karir dan ambisi) pada satu sisi dan kehidupan (kebahagiaan, waktu luang, keluarga dan pengembangan spiritual) di sisi lain (Singh dan Khanna, 2011).

Hasil penelitian terdahulu didapatkan bahwa Worklife Balance berpengaruh positif dan signifikan terhadap OCB dan Kinerja Karyawan. Sejalan dengan penelitian sebelumnya yang menunjukkan bahwa Worklife Balance yang dirasakan memiliki pengaruh besar pada komitmen dan produktivitas karyawan (Eby et al., 2005) juga mendukung survei empiris yang dilakukan oleh Podsakoff et al. (2000) dengan garis bawah yang muncul Worklife Balance untuk mempromosikan keterlibatan karyawan dalam Organizational Citizenship Behavior (OCB) yang mungkin bermanfaat bagi organisasi melalui positif efektivitas. Sejalan dengan penelitian Krishnan et al. (2018) yang menguji peran / pengaruh langsung dari kepuasan kerja dan Worklife Balance pada kinerja tugas staf akademik di lembaga pendidikan tinggi publik yang dipilih di Malaysia. Temuan penelitian menunjukkan hubungan positif antara kepuasan kerja dan Worklife Balance pada kinerja tugas akademisi. Lebih khusus, Worklife Balance telah terbukti memiliki hasil positif, seperti niat turnover rendah, peningkatan kinerja, dan kepuasan kerja (Cegarra-leiva et al., 2012).

Selanjutnya ditemukan stress kerja berpengaruh negatif dan signifikan terhadap OCB dan Kinerja. Ali \& Soo (2016) yang meneliti Kaitan Antara Stres dan OCB menemukan hubungan antara stress dan OCB adalah negatif dan stres kerja berpengaruh signifikan terhadap OCB. Hasil penelitian lain menemukan bahwa karyawan yang mengalami kesulitan dalam mengikuti pekerjaan akan menganggap OCB sebagai gangguan yang mencegah merekamemenuhi tujuan yang terkait dengan pekerjaan (Boyd et al., 2011). Konflik pekerjaan dengan keluarga juga menciptakan tekanan pada karyawan suatu organisasi (Anderson et al., 2002). Stres negatif memengaruhi kesehatan fisik dan mental karyawan yang pada gilirannya mempengaruhi kinerja mereka di tempat kerja (Ratnawat \& Jha, 2014).

Peran OCB dalam memediasi Worklife Balance dan Stres Kerja terhadap Kinerja Karyawan, ditemukan bahwa OCB dapat memediasi sebagian atau partial mediating. Harikaran \& Thevanes (2018) menemukan ketika karyawan merasa didukung oleh organisasi mereka, mereka menjadi lebih berkomitmen dan puas, bersedia untuk terlibat dalam OCB di tempat kerja. Murali et al. (2017) meneliti tentang Dampak stres kerja pada kinerja karyawan, menemukan tekanan waktu dan ambiguitas peran berpengaruh signifikan dan negatif terhadap kinerja karyawan. Didukung Penelitian Ali \& Soo (2016) tentang Kaitan Antara Stres dan Organizational Citizenship Behavior (OCB). Menemukan hubungan negatif antara stress dan Organizational Citizenship Behavior (OCB). 


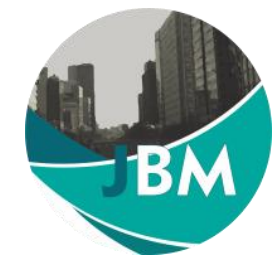

\section{Metode Penelitian}

Penelitian ini menggunakan jenis penelitian kuantitatif dengan pendekatan explanatory. Metode yang digunakan dalam penelitian ini menggunakan cross-sectional. Pengumpulan data dalam penelitian ini dilakukan pada tahun 2020. Penelitian ini dilakukan pada seluruh karyawan PT PLN (Persero) UP2B Sumbagteng, menggunakan metode sensus yaitu sebanyak 50 orang. Jenis data yang digunakan dalam penelitian ini adalah data primer yang diperoleh melalui penyebaran kuesioner. Metode analisis data yang digunakan adalah analisis jalur (path analysis). Teknik Analisis data yang digunakan partial least square.

Hasil

\section{Model Pengukuran (Outer Model)}

Ukuran reflektif individual dikatakan tinggi jika berkorelasi lebih dari 0.7 dengan konstruk yang ingin diukur. Pada penelitian untuk tahap awal dari pengembangan skala pengukuran, nilai loading 0.50 sampai 0.60 dianggap cukup (Ghozali, 2015). Nilai loading dari masing-masing indikator variabel penelitian dapat dilihat pada Gambar 1.

\section{Gambar 1 Output Outer test}

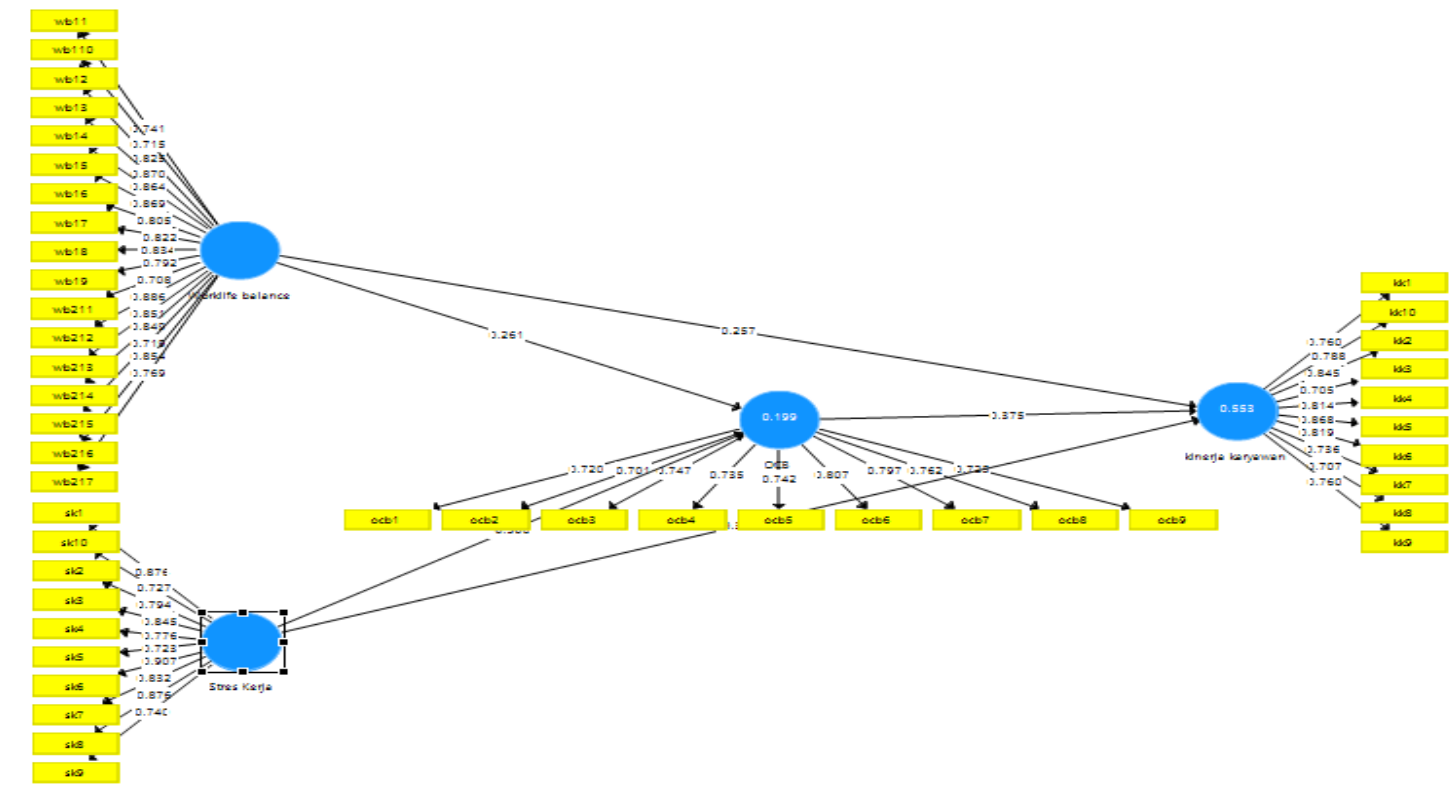

Sumber: Data Sekunder Diolah (2020)

Gambar 1 menunjukkan bahwa indikator dari masing-masing variabel penelitian dapat dikatakan valid, karena telah memenuhi convergent validity di mana nilai loading dari instrumen penelitian $>0.70$. Hal ini mengindikasikan bahwa setiap instrumen dari variabel penelitian sudah dapat bekerja sesuai fungsinya. Jika nilai akar kuadrat (square root of average) AVE setiap konstruk lebih besar dari nilai korelasi antar konstruk dalam model, maka dapat dikatakan bahwa konstruk memiliki tingkat validitas yang baik. Nilai discriminant validity dapat dilihat pada Tabel 2.

Tabel 2. Discriminant validity

\begin{tabular}{ccccc} 
& OCB & Stres Kerja & Worklife Balance & Kinerja karyawan \\
\hline OCB & 0,749 & & & \\
SK & $-0,367$ & 0,812 & & \\
WB & 0,332 & $-0,232$ & 0,812 & 0,782 \\
KK & 0,596 & $-0,567$ & 0,468 & 0,782 \\
\hline
\end{tabular}

Sumber: Data Sekunder Diolah (2020) 
Tabel 2 menunjukkan bahwa setiap variabel yang digunakan dalam penelitian ini dikatakan valid. Hal itu disebabkan oleh nilai akar kuadrat AVE setiap variabel lebih besar dibandingkan dengan korelasi antara variabel dengan variabel lainnya. Selanjutnya, uji reliabilitas dilakukan untuk menguji konsistensi atau keandalan suatu instrumen penelitian dalam mengukur suatu konsep. Uji reliabilitas dapat diukur dengan dua kriteria yaitu composite reliability dan cronbach alpha. Suatu variabel dikatakan reliabel apabila nilai composite reliability dan cronbach alpha di atas 0.70 . Hasil composite reliability dapat dilihat pada Tabel 3 .

Tabel 3. Composite reliability

\begin{tabular}{lcccc} 
& Cronbach's Alpha & rho_A & $\begin{array}{c}\text { Composite } \\
\text { Reliability }\end{array}$ & $\begin{array}{c}\text { Average Variance } \\
\text { Extracted (AVE) }\end{array}$ \\
\hline OCB & 0,902 & 0,910 & 0,920 & 0,561 \\
Stres Kerja & 0,942 & 0,957 & 0,951 & 0,659 \\
Worklife balance & 0,968 & 0,978 & 0,970 & 0,660 \\
Kinerja Karyawan & 0,929 & 0,933 & 0,940 & 0,611 \\
\hline
\end{tabular}

Sumber: Data Sekunder Diolah (2020)

Tabel 3 menunjukkan bahwa semua variabel dalam penelitian ini reliabel karena nilai composite reliability dan cronbach alpha setiap variabel $>0.70$. Selain itu, nilai AVE setiap variabel $>0.5$.

\section{Model Struktural (Inner Model)}

Pengujian terhadap model struktural (inner model) dilakukan dengan melihat nilai R-Squared yang merupakan uji goodness of fit. Penelitian dengan model PLS, dimulai dengan melihat nilai R-Squared untuk setiap variabel endogen (variabel dependen). Perubahan nilai R-Squared dapat digunakan untuk melihat pengaruh variabel eksogen (variabel independen) terhadap variabel endogen (variabel dependen), apakah mempunyai pengaruh yang substantif. Model struktural dalalm penelitian ini dapat dilihat pada Tabel 4.

Tabel 4. Nilai R-Squared

\begin{tabular}{lcc}
\hline & R-Square & R-Square Adjusted \\
OCB & 0,199 & 0,165 \\
Kinerja Karyawan & 0,553 & 0,524 \\
\hline
\end{tabular}

Sumber: Data Sekunder Diolah (2020)

Tabel 4 menunjukan nilai $R$-Square untuk variabel OCB adalah 0.199. Artinya, OCB dipengaruhi oleh Worklife Balance dan Stres Kerja sebesar 19.9\%, sedangkan sisanya $80.1 \%$ dipengaruhi faktor lain. Nilai $R$-Squared dari variabel Kinerja Karyawan adalah 0.553. Artinya, Worklife Balance dan Stres Kerja mempengaruhi Kinerja Karyawan sebesar $55.3 \%$, sedangkan sisanya $44.7 \%$ dipengaruhi faktor lain. Semakin tinggi nilai $R$-Squared, maka semakin besar kemampuan variabel eksogen dalam menjelaskan variabel endogen sehingga persamaaan struktural akan semakin baik.

\section{Pengujian Hipotesis}

Pengujian hipotesis dilakukan dengan menggunakan bootstrapping pada SmartPLS 3.0. Apakah hipotesis diterima atau ditolak dapat dilakukan dengan melihat nilai probabilitas dan T-Statistik. Hipotesis akan diterima apabila nilai TStatistik > T-Tabel (1.96) dan P Values < 0.05 dengan tingkat kepercayaan $95 \%(\alpha=0.05)$. Pengujian hipotesis pertama ini dilakukan untuk melihat pengaruh langsung antar variabel. Dapat dilihat pada Tabel 5.

\section{Tabel 5. Path coefficient \& hipotesis}

\begin{tabular}{cccccc} 
& $\begin{array}{c}\text { Original Sample } \\
(\mathrm{O})\end{array}$ & $\begin{array}{c}\text { Sample } \\
\text { Mean (M) }\end{array}$ & $\begin{array}{c}\text { Standard Deviation } \\
\text { (STDEV) }\end{array}$ & $\begin{array}{c}\text { T Statistics } \\
(\text { O/STDEV })\end{array}$ & P Values \\
\hline OCB $>$ KK & 0,375 & 0,349 & 0,138 & 2,726 & 0,007 \\
SK $>$ OCB & $-0,306$ & $-0,310$ & 0,132 & 2,325 & 0,020 \\
SK $>$ KK & $-0,369$ & $-0,386$ & 0,166 & 2,218 & 0,027 \\
WB $>$ OCB & 0,261 & 0,290 & 0,114 & 2,281 & 0,023 \\
WB $>$ KK & 0,257 & 0,272 & 0,107 & 2,398 & 0,017 \\
\hline
\end{tabular}

Sumber: Data Sekunder Diolah (2020) 


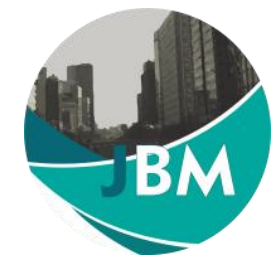

Berdasarkan Tabel 5, dapat disimpulkan bahwa hipotesis 1-5 pada penelitian ini berpengaruh dan signifikan. Hipotesis 1-5 diterima dengan melihat nilai probabilitas dan T-Statistik yang menunjukkan nilai T-Statistik > T-Tabel (1.96) dan $P$ Values $<0.05$ dengan tingkat kepercayaan $95 \%(a=0.05)$. Selanjutnya, pengujian hipotesis kedua untuk melihat efek mediasi. Efek mediasi dalam penelitian ini yaitu uji pengaruh tidak langsung variabel Worklife Balance dan Stres Kerja dengan variabel Kinerja Karyawan melalui variabel OCB. Hasil pengujian dapat dilihat pada Tabel 6.

Tabel 6. Specific indirect effect \& hipotesis

\begin{tabular}{lccccc} 
& $\begin{array}{c}\text { Original } \\
\text { Sample (0) }\end{array}$ & $\begin{array}{c}\text { Sample Mean } \\
(\mathrm{M})\end{array}$ & $\begin{array}{c}\text { Standard } \\
\text { Deviation } \\
(\text { STDEV })\end{array}$ & $\begin{array}{c}\text { T Statistics } \\
(\mid \text { O/STDEV|) }\end{array}$ & $\begin{array}{c}\text { P } \\
\text { Values }\end{array}$ \\
\hline $\begin{array}{l}\text { Worklife balance }->\text { OCB }>\text { Kinerja } \\
\text { Karyawan }\end{array}$ & 0,098 & 0,100 & 0,061 & 1,613 & 0,107 \\
$\begin{array}{l}\text { Stres Kerja }>\text { OCB }>\text { Kinerja } \\
\text { Karyawan }\end{array}$ & $-0,115$ & $-0,108$ & 0,067 & 1,719 & 0,086 \\
\hline
\end{tabular}

Sumber: Data Sekunder Diolah (2020)

Kemudian untuk melihat bentuk efek mediasi pada hipotesis 6 dan 7 maka dilakukan uji Variance Accounted for (VAF) dengan rumus sebagai berikut:

$\begin{aligned} \text { VAF } & =\frac{\text { Indirect Effect }}{\text { Direct Effect }+ \text { Indirect Effect }} \\ \text { VAF } & =\frac{0,098}{0,257+0,098} \\ \text { VAF } & =0,2761 \times 100 \% \\ \text { VAF } & =27,61 \% \text { atau } 28 \%\end{aligned}$

Hasil uji Variance Accounted for (VAF) variabel mediasi OCB antara hubungan variabel Worklife Balance dan Kinerja karyawan menghasilkan nilai VAF sebesar 28\%. Maka jenis efek mediasi adalah mediasi sebagian (partial mediation).

$$
\begin{aligned}
\text { VAF } & =\frac{-0,115}{(-0,369)+(-0,115)} \\
\text { VAF } & =0,2376 \times 100 \% \\
\text { VAF } & =23,76 \% \text { atau } 24 \%
\end{aligned}
$$

Hasil uji Variance Accounted For (VAF) variabel mediasi OCB antara hubungan variabel Stres Kerja dengan KInerja Karyawan menghasilkan nilai VAF sebesar $24 \%$. Maka jenis efek mediasi adalah mediasi sebagian (partial mediation).

\section{Pembahasan}

\section{Pengaruh Worklife Balance terhadap Kinerja Karyawan}

Berdasarkan uji hipotesis dalam penelitian ini ditemukan bahwa Worklife Balance berpengaruh positif signifikan terhadap kinerja karyawan PT PLN (Persero) UP2B Sumbagteng. Di beberapa penelitian terdahulu juga menemukan bahwa Worklife Balance mempunyai pengaruh terhadap Kinerja Karyawan (Bataineh, 2019), (Murthy \& Guthrie, 2012), (Krishnan et al., 2018), (Cegarra-leiva et al., 2012). Menariknya antara Worklife Balance dan Kinerja Karyawan pun begitu, harus sejalan satu sama lain. Apabila karyawan merasa bahwa pekerjaan sudah mengganggu kehidupan pribadinya atau urusan pribadi sudah mengganggu pekerjaan dengan kata lain sudah tidak ada keseimbangan antara keduanya maka dikhawatirkan karyawan mengambil keputusan untuk meninggalkan pekerjaan, menjadi demitivasi dan menjadi penyebab menurunnya Kinerja karyawan. Disini diharapkan perhatian dari perusahaan untuk meningkatkan 
hal-hal apa saja yang menjadi motivasi karyawan bekerja terkait Worklife Balance. Memperbaiki iklim dan budaya perusahaan sehingga karyawan semakin betah dan meningkatkan kreatifitasnya dalam bekerja, karena ini akan berdampak langusng pada Kinerja.

\section{Pengaruh Stres Kerja terhadap Kinerja Karyawan}

Hipotesis II yang didapatkan setelah pengujian hipotesis Stres Kerja terhadap Kinerja Karyawan adalah berpengaruh negatif (nilai koefisien $-0,369)$ dan signifikan $(p=0,027<0,05)$ dengan demikian maka dapat dinyatakan bahwa stres kerja berpengaruh Negatif dan signifikan terhadap kinerja karyawan. Hasil tersebut didukung dengan penelitian terdahulu yang dilakukan oleh (Ahmed, 2013), (Ratnawat \& Jha, 2014), (Khuong \& Yen, 2016) dan (Altangerel et al., 2015). Stres bisa berdampak buruk bagi karyawan berupa kekhawatiran atau ketakutan agresi, apatis, rasa bosan, depresi, keletihan, frustasi, kehilangan kendali emosi, penghargaan diri yang rendah, gugup, kesepian. Sedangkan dampak stres terhadap organisasi berupa produktivitas rendah, terasing dari mitra kerja, komitmen organisasi dan loyalitas berkurang.

\section{Pengaruh Worklife balance terhadap OCB}

Berdasarkan uji hipotesis menunjukkan bahwa Worklife Balance mempunyai pengaruh yang positif (nilai koefisien $0,261)$ dan signifikan $(p=0,023<0,05)$ terhadap OCB, oleh karena itu hipotesis III diterima. Hasil ini menunjukkan bahwa semakin tinggi Worklife Balance yang didapatkan oleh karyawan maka akan semakin tinggi OCB dari karyawan tersebut. Hal ini diperkuat oleh penelitian yang dilakukan oleh (Pradhan et al., 2016) menyebutkan bahwa terdapat pengaruh yang positif dan signifikan antara Worklife Balance terhadap OCB. Keseimbangan antara kehiduapn pribadi dan pekerjaan pada karyawan memberikan kenyamanan dan fokus dalam bekerja, suasana hati yang lebih baik beraktifitas, memiliki hubungan yang baik dengan rekan kerja akan mendorong karyawan untuk melakukan Organizational Citizenship Behavior (OCB). Karyawan akan senang hati membantu rekan kerjanya yang kewalahan menyelesaikan pekerjaan, menjaga loyalitas dan integritas pada perusahaan.

\section{Pengaruh Stres Kerja terhadap Organizational Citizenship Behavior (OCB)}

Nilai yang di dapatkan dari pengujian hipotesis keempat yaitu Stres Kerja terhadap OCB didapatkan hasil pengaruh negatif (nilai koefisien $-0,306)$ dan signifikan $(p=0,020<0,05)$ dari hasil tersebut maka dapat dinyatakan bahwa Worklife Balance berpengaruh negatif dan signifikan terhadap OCB. Hasil tersebut didukung oleh hasil penelitian terdahulu yang dilakukan oleh (Ali \& Soo, 2016) dan (Pooja et al., 2016). Sejalan dengan hasil penelitian Bouckenooghe et al. (2013) bahwa OCB dilemahkan pada tingkat interaksi sosial yang lebih tinggi karena kelebihan Beban Kerja dan interpersonal konflik pada karyawan. Tekanan akibat konflik interpersonal dengan kolega mengurangi OCB karyawan. Ketika karyawan mengalami konflik interpersonal tingkat tinggi, mereka cenderung fokus pada penyelesaian masalahmasalah relasional itu daripada pada tugas yang berhubungan dengan pekerjaan. Oleh karena itu masalah stress Kerja ini perlu mendapat perhatian bagi perusahaan karena terkait dengan interaksi antar karyawan dan mendukung Suasana nyaman dalam bekerja.

\section{PengaruhOrganizational Citizenship Behavior (OCB) terhadap Kinerja Karyawan}

Berdasarkan hasil pengujian hipotesis 5 dalam penelitian ini, ditemukan bahwa OCB berpengaruh positif dan signifikan terhadap Kinerja Karyawan. Dimana nilai T Statistik $(2,726)>$ T Tabel $(1,96)$ dan P Values $(0,007)<0,050$ sehingga hipotesis 5 diterima Sejalan dengan penelitian yang dilakukan oleh Prabasari et al. (2018), Chelagat et al. (2015), dan Putrana et al. (2016) menyatakan bahwa OCB berdampak positif dan signifikan terhadap Kinerja Karyawan. Sesuai dengan hasil penelitian Fitriastuti (2016) menunjukkan bahwa OCB berpengaruh positif terhadap kinerja. Aktivitas menolong rekan kerja lain akan mempercepat penyelesain tugas rekan kerjanya, dan pada gilirannya meningkatkan produktivitas kinerja rekan tersebut.

\section{Peran OCB Memediasi Pengaruh Worklife Balance Terhadap Kinerja Karyawan}

Berdasarkan penghitungan yang telah dilakukan, di dapatkan hasil yaitu OCB memiliki efek mediasi antara Worklife Balance terhadap Kinerja Karyawan dengan nilai 20\% $\leq 27,61 \% \leq 80 \%$ dengan jenis mediasinya yaitu mediasi parsial. Hasil tersebut didukung oleh penelitian yang dilakukan oleh (Harikaran \& Thevanes, 2018) dan (Beham, 2011). Dari hasil tersebut dapat dijelaskan bahwa, Worklife Balance akan memiliki pengaruh yang lebih signifikan terhadap Kinerja Karyawan jika dimediasi oleh OCB. Worklife Balancemendukung sikap OCB yang nantinya akan berdampak baik kepada karyawan baik itu dampak terhadap psikologis, fisiologis maupun kinerjanya. Parsial mediasi artinya OCB bukan merupakan satu-satunya variabel yang dapat memediasi Worklife Balance terhadap Kinerja Karyawan. Tidak 


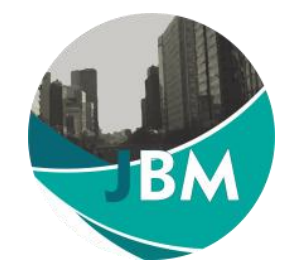

hanya itu Worklife Balance juga dapat berpengaruh terhadap kinerja tanpa adanya efek mediasi dari OCB.

\section{Peran OCB Memediasi Antara Stres Kerja Terhadap Kinerja Karyawan}

Berdasarkan uji hipotesis menyebutkan bahwa OCB hanya dapat memediasi sebagian atau partial mediating karena nilai VAF (variance accounted for) yaitu $23,76 \%$. Oleh karena itu nilai VAF terletak antara $20 \%-80 \%$ yang berarti memiliki pengaruh sebagian atau partial mediating (Hair Jr et al., 2010). Hal ini berarti bahwa OCB hanya dapat memediasi sebagian dari Stres Kerja terhadap Kinerja Karyawan. Jadi, semakin tidak diperhatikannya Stres Kerja akan mempengaruhi Kinerja Karyawan hanya dapat dimediasi sebagian (partial) oleh OCB, berarti secara langsung Stres Kerja memiliki pengaruh yang lebih besar terhadap Kinerja Karyawan. Stres kerja (tekanan waktu, kurang motivasi, Worklife Balance, peran ambigu) berpengaruh signifikan dan negatif terhadap kinerja karyawan (Murali et al., 2017). Didukung Penelitian Ali \& Soo (2016) tentang Kaitan Antara Stres dan OCB. Menemukan hubungan negatif antara stress dan OCB.

\section{Kesimpulan}

Berdasarkan hasil analisis dan pembahasan, maka dapat diambil kesimpulan bahwa Worklife Balance berpengaruh positif dan signifikan terhadap OCB dan Kinerja Karyawan PT PLN (Persero) UP2B Sumbagteng, Ini berarti bahwa semakin tinggi penerapan praktek Worklife Balance maka OCB dan Kinerja Karyawan juga akan semakin meningkat, dan sebaliknya. Karyawan yang merasa puas dan nyaman dalam aktifitas pribadi dan berenergi untuk melaksanakan pekerjaan akan membawa hal-hal yang positif, salah satunya cenderung secara sukarela mau membantu rekan kerja yang kesulitan dalam menyelesaikan pekerjaannya dan sanggup memenuhi aturan dan peraturan perusahaan. Stres Kerja berpengaruh negatif dan signifikan terhadap OCB dan Kinerja Karyawan PT PLN (Persero) UP2B Sumbagteng. Hal ini diartikan sebagai semakin rendah tingkat stres karyawan maka OCB dan Kinerja Karyawan akan tinggi, sebaliknya semakin tinggi tingkat stres karyawan maka mereka cenderung tidak bisa menyelesaikan pekerjaan dengan baik, pekerjaan terbengkalai, kesehatan terganggu dan tentu saja ini juga menghalangi mereka untuk dapat membantu rekan kerja lain yang membutuhkan bantuan.

Hasil Penelitian juga menemukan bahwa OCB berpengaruh positif dan signifikan terhadap Kinerja Karyawan PT PLN (Persero) UP2B Sumbagteng artinya jika mayoritas karyawan sanggup berperilaku OCB maka akan meningkat Kinerja karyawan secara keseluruhan. Sikap yang patuh pada aturan perusahaan, memiliki hubungan yang baik dalam lingkungan kantor serta mengikuti perkembangan organisasi akan meningkatkan loyalitas dan integritas karyawan. OCB memediasi secara parsial pengaruh antara Worklife Balance terhadap Kinerja Karyawan PT PLN (Persero) UP2B Sumbagteng artinya Meningkatnya Worklife Balance akan memberikan sikap positif terhadap Kinerja Karyawan dan akan meningkatkan Sikap OCB pada mayoritas karyawan. OCB juga mengidentifikasikan bahwa mereka selalu menjaga keseimbangan dalam kehidupan pribadi dan melaksanakan tugas di perusahaan. Adanya sikap positif OCB terhadap Worklife Balance memicu timbulnya niat untuk meningkatkan Kinerja. Selanjutnya OCB memediasi pengaruh Stres Kerja terhadap Kinerja Karyawan PT PLN (Persero) UP2B Sumbagteng artinya apabila karyawan menghadapi banyak masalah dalam kehidupan pribadi maupun di perusahaan yang berujung mengalami stress kerja makan akan menghalangi terbentuknya sikap OCB. Hal ini akan menggangu karyawan dalam melaksanakan pekerjaan, mengikuti aktifitas dan aturan perusahaan, hilang semangat dalam bekerja maka ini akan menurunkan Kinerja Karyawan.

\section{Saran}

Adapun beberapa saran yang diajukan agar dapat menjadi masukan bagi pengembangan penelitian selanjutnya dengan menambah variabel lain yang dapat menjelaskan lebih mendalam tentang Kinerja Karyawan, Seperti Kecerdasan spriritual, job satisfaction, job enviroment dan banyak lagi variabel yang bisa dijadikan acuan untuk mengetahui pengaruhnya terhadap Kinerja Karyawan. Selanjutnya diharapkan juga penelitian nanti dapat mengambil sampel pada karyawan PT PLN (Persero) unit lainnya yang masih dalam satu grup PT PLN (Persero), agar kajian tentang variabel Worklife Balance, Stres Kerja, Organizational Citizenship Behavior (OCB) dan Kinerja Karyawan dapat dipahami secara mendalam. Dengan memperhatikan hasil dari penelitian, guna memperbaiki kekurangan diharapkan agar penelitian selanjutnya sebaiknya jumlah sampel yang digunakan lebih banyak, menggunakan data yang terbaru dan memperluas objek penelitian. Agar penelitian memberikan hasil yang lebih relevan dan lebih akurat. 
Volume 8, No 1 (64-74), 2021

\section{Daftar Pustaka}

Ahmed, A. (2013). Effects of Job Stress on Employees Job Performance A Study on Banking Sector of Pakistan. IOSR Journal of Business and Management, 11(6), 61-68. https://doi.org/10.9790/487x-1166168

Ali, H., \& Soo, H. S. (2016). The Linkage Between Stress and Organizational Citizenship Behavior. Medwell Journals, a993-5250.

Altangerel, O., Ruimei, W., Elahi, E., \& Dash, B. (2015). Investigating The Effect Of Job Stress On Performance Of Employees. International Journal of Scientific \& Technology Research, 4(2), 276-280.

Bataineh, K. adnan. (2019). Impact of Work-Life Balance, Happiness at Work, on Employee Performance. International Business Research, 12(2), 99. https://doi.org/10.5539/ibr.v12n2p99

Beham, B. (2011). Work-family conflict and organisational citizenship behaviour: Empirical evidence from Spanish employees. Community, Work and Family, 14(1), 63-80. https://doi.org/10.1080/13668803.2010.506034

Bouckenooghe, D., Clercq, D. De, \& Deprez, J. (2013). Interpersonal Justice, Relational Conflict , and Commitment to Change: The Moderating Role of Social Interaction. International Association of Applied Psychology, 1-32. https://doi.org/10.1111/apps.12006

Bruggen, A. (2015). An empirical investigation of the relationship between workload and performance. Management Decision, 53(10). https://doi.org/10.1108/md.2007.00145fab.001

Cegarra-leiva, D., Cegarra, J. G., \& Vidal, E. S. (2012). Work life balance and the retention of managers in Spanish SMEs WORK LIFE BALANCE AND THE RETENTION OF MANAGERS IN. The International Journal of Human Resource Management. https://doi.org/10.1080/09585192.2011.610955

Chelagat, L. J., Chepkwony, P. K., \& Kemboi, A. (2015). Effect of organizational citizenship behavior on employee performance in banking sector, Nairobi County, Kenya. International Journal of Business, Humanities and Technology, 5(4), 55-61.

Djati, S. P. (2018). Variabel Anteseden Organizational Citizenship Behavior (OCB) dan Pengaruhnya terhadap Service Quality pada Perguruan Tinggi Swasta di Surabaya (pp. 121-131). ISSN : 1693-5241.

Fisher, G. G., Bulger, C. A., \& Smith, C. S. (2009). Beyond Work and Family: A Measure of Work/Nonwork Interference and Enhancement. Journal of Occupational Health Psychology, 14(4), 441-456. https://doi.org/10.1037/a0016737

Fitriastuti, T. (2016). Pengaruh Kecerdasan Emosional, Komitmen Organisasi, Dan Organizational Citizenship Behavior Terhadap Kinerja Pegawai Feb. E-Jurnal Manajemen Universitas Udayana, 5(2), 254986.

Frame, P., \& Hartog, M. (2003). From rhetoric to reality. Into the swamp of ethical practice: implementing work-life balance. Business Ethics: A European Review, 12(4), 358-368. https://doi.org/10.1111/1467-8608.00337

Glazer, S., \& Beehr, T. A. (2005). Consistency of implications of three role Stressors across four countries. Journal of Organizational Behavior, 26(5), 467-487. https://doi.org/10.1002/job.326

Greenhaus, J. H., Collins, K. M., \& Shaw, J. D. (2003). The relation between work-family balance and quality of life. Journal of Vocational Behavior, 63(3), 510-531. https://doi.org/10.1016/S0001-8791(02)00042-8

Hair Jr, J. F., Black, W. C., Babin, B. J., \& Anderson, R. E. (2010). Multivariate Data Analysis (7th ed.). Pearson Prentice Hall, All right reserved.

Harikaran, S., \& Thevanes, N. (2018). The Relationships among Work-Life Balance, Organizational Citizenship Behavior and Organizational Performance : A Review of Literature. 20(8), 25-31. https://doi.org/10.9790/487X2008052531

Hassan, S., Hassan, M. U., \& Shoaib, M. (2014). Measuring the impact of perceived organization support, psychological empowerment and rewards on employees' satisfaction: Testing the mediating impact of employee engagement. World Applied Sciences Journal, 30(5), 652-660. https://doi.org/10.5829/idosi.wasj.2014.30.05.14094

Khazaei, K., Khalkhali, A., \& Eslami, N. (2011). Relationship between organizational citizenship behavior and performance of school teachers in west of Mazandaran province. World Applied Sciences Journal, 13(2), 324330.

Khuong, M. N., \& Yen, V. H. (2016). Investigate the Effects of Job Stress on Employee Job Performance - A Case Study at Dong Xuyen Industrial Zone, Vietnam. International Journal of Trade, Economics and Finance, 7(2), 3137. https://doi.org/10.18178/ijtef.2016.7.2.495

Krishnan, R., Loon, K. W., \& Tan, N. Z. (2018). The Effects of Job Satisfaction and Work-Life Balance on Employee Task Performance. International Journal of Academic Research in Business and Social Sciences, 8(3), 652-662. 


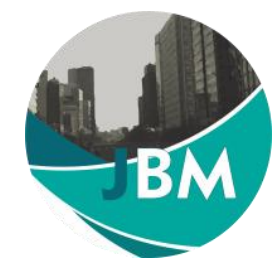

https://doi.org/10.6007/ijarbss/v8-i3/3956

Maharani, V., Troena, E. A., \& Noermijati. (2013). Organizational Citizenship Behavior Role in Mediating the Effect of Transformational Leadership, Job Satisfaction on Employee Performance: Studies in PT Bank Syariah Mandiri Malang East Java. International Journal of Business and Management, 8(17), 1-12. https://doi.org/10.5539/ijbm.v8n17p1

Murali, S. B., Basit, A., \& Hassan, Z. (2017). Impact of Job Stress on Employee Job Satisfaction. International Journal of Accounting \& Business Management, 5(2). https://doi.org/24924/ijabm/2017.11/v5.iss2/13.33

Murthy, V., \& Guthrie, J. (2012). Management control of work-life balance. A narrative study of an Australian financial institution. Journal of Human Resource Costing \& Accounting, 16(4), 258-280. https://doi.org/10.1108/14013381211317248

Poohongthong, C., Surat, P., \& Sutipan, P. (2014). A Study on the Relationships between Ethical Leadership , Worklife Balance, Organizational Socialization, and Organizational Citizenship Behavior of Teachers in Northern Thailand. 9(2), 17-28.

Pooja, A. A., De Clercq, D., \& Belausteguigoitia, I. (2016). Job Stressors and Organizational Citizenship Behavior: The Roles of Organizational Commitment and Social Interaction. Human Resource Development Quarterly, 27(3), 373-405. https://doi.org/10.1002/hrdq.21258

Prabasari, I. G. A. M., Martini, L. K. B., \& Suardika, N. (2018). The Effect of Communication and Employee Engagement on Organizational Citizenship Behavior and Employee Performance in Employees Pt. Pln (Persero) Distribution of Bali. International Journal of Contemporary Research and Review, 9(08), 21014-21025. https://doi.org/10.15520/ijcrr/2018/9/08/586

Pradhan, R. K., Jena, L. K., \& Kumari, I. G. (2016). Effect of Work-Life Balance on Organizational Citizenship Behaviour: Role of Organizational Commitment. Global Business Review, 17, 15S-29S. https://doi.org/10.1177/0972150916631071

Putrana, Y., Fathoni, A., \& Warso, M. M. (2016). Pengaruh Kepuasan Kerja dan Komitmen Organisasi terhadap Organizational Citizenship Behavior dalam meningkatkan Kinerja Karyawan pada PT. Gelora Persada Mediatama Semarang. Journal Of Management, 2(2).

Ratnawat, R. G., \& Jha, P. C. (2014). Impact of Job Related Stress on Employee Performance : A Review and Research Agenda. IOSR Journal of Business and Management, 16(11), 1-6.

Rousseau, V., \& Aubé, C. (2010). The Journal of Social Social Support at Work and Affective Commitment to the Organization : The Moderating Effect of Job Resource Adequacy and Ambient Conditions. The Journal of Social Psychology, 37-41. https://doi.org/10.1080/00224540903365380

Sekaran, U., \& Bougie, R. (2016). Research Methods for Business (7th ed.). John Wiley \& Sons Ltd. https://doi.org/10.1017/CBO9781107415324.004

Sen, C., \& Hooja, H. (2015). Psychological capital and work-life balance: a study on police offciers. International Journal of Management and Social Sciences Research (IJMSSR), 4(7), 93-96. https://doi.org/ijmssr/July2015/15.pdf

Supriyanto, A. S. (2013). Role of Procedural Justice, Organizational Commitment and Job Satisfaction on job Performance: The Mediating Effects of Organizational Citizenship Behavior. International Journal of Business and Management, 8(15), 57-67. https://doi.org/10.5539/ijbm.v8n15p57

Thevanes, N., \& Arulrajah, A. (2017). The Relationships Among Environmental Training, Environmental Attitude of Employee, Environmental Behavior of Employee and Environmental Orientation of Organization: A Review of Literature. SSRN Electronic Journal, Juice, 61-67. https://doi.org/10.2139/ssrn.2909687

Triyanto, A., \& Santosa, T. (2009). Organizational Citizenship Behavior (OCB) Dan Pengaruhnya Terhadap Keinginan Keluar Dan Kepuasan Kerja Karyawan. Jurnal Manajemen Maranatha, 8(2), 52-65.

Wright, T. A., \& Cropanzano, R. (2000). Psychological well-being and job satisfaction as predictors of job performance Psychological Well-Being and Job Satisfaction as Predictors of Job Performance. Journal of Occupational Health Psycholog, 5(1), 84-94. https://doi.org/10.1037/1076-8998.5.1.84

Yozgat, U., Yurtkoru, S., \& Bilginoğlu, E. (2013). Job Stress and Job Performance Among Employees in Public Sector in Istanbul: Examining the Moderating Role of Emotional Intelligence. Procedia - Social and Behavioral Sciences, 75, 518-524. https://doi.org/10.1016/j.sbspro.2013.04.056 